\section{AB024. A case of bullous systemic lupus erythematosus confined to the oral mucosa}

\author{
Jennifer Strunck, Lynne Morrison, Teri Greiling \\ Department of Dermatology, Oregon Health and Science University, \\ Portland, OR, USA \\ Correspondence to: Teri Greiling. 3303 SW Bond Avenue, Mailcode: \\ CH16D, Portland, OR 97239, USA. Email: greiling@ohsu.edu.
}

\begin{abstract}
Bullous systemic lupus erythematosus (BSLE) is a rare antibody-mediated blistering disease that presents in association with systemic lupus erythematosus (SLE). Features of BSLE can present as a diagnostic challenge as they often mimic other bullous skin diseases. We present a case of a 45-year-old female with history of celiac disease, Raynaud's syndrome, chilblains, and Sicca symptoms who presented with 10 months of recurrent vesicles and erosions of the gingiva. Review of symptoms was positive for arthralgias and recurrent photosensitive rashes. Physical examination was notable for multiple $4 \mathrm{~mm}$ vesicles with mild surrounding erythema confined to anterior upper gingiva without further mucosal or cutaneous involvement. Two biopsies obtained prior to presentation revealed a mixed inflammatory infiltrate with focal eosinophils, negative for viral cytopathic changes. A biopsy of the maxillary frenum for direct immunofluorescence (DIF) demonstrated a weak, fine linear deposition of $\operatorname{IgG}$ and $\mathrm{IgA}$ along the basement membrane zone initially suspicious for mucous membrane pemphigoid. Serum ELISA for antibodies against BP180, BP230, and collagen VII were
\end{abstract}

negative. Further lab workup was notable for an ANA of 1:160, anti-Ro60 774 (normal 0-19), anti-Sm 20.7 (normal $0-19$ ), and C4 15.1 (normal 16.3-47.8). The patient was found to meet SLICC criteria (joint disease, chronic cutaneous lupus (chilblains), positive ANA, positive Anti$\mathrm{Sm}$, and low C4) for SLE diagnosis. The patient was started on dapsone $100 \mathrm{mg}$ by mouth daily with improvement in symptoms. BSLE can affect the oral mucosa and has been described in the absence of anti-collagen VII positivity, but has not been described in the absence of cutaneous bullae. Although atypical, the DIF staining pattern in the context of SLE raises support for a diagnosis of oral BSLE. Teaching point: BSLE can manifest as an oral vesicular eruption and can be differentiated from other oral bullous diseases based on histologic and immunopathologic features

Keywords: Bullous systemic lupus erythematosus (BSLE); lupus; bullous disease

doi: 10.21037/atm.2021.AB024

Open Access Statement: This is an Open Access article distributed in accordance with the Creative Commons Attribution-NonCommercial-NoDerivs 4.0 International License (CC BY-NC-ND 4.0), which permits the noncommercial replication and distribution of the article with the strict proviso that no changes or edits are made and the original work is properly cited (including links to both the formal publication through the relevant DOI and the license). See: https://creativecommons.org/licenses/by-nc-nd/4.0/.

Cite this abstract as: Strunck J, Morrison L, Greiling T. A case of bullous systemic lupus erythematosus confined to the oral mucosa. Ann Transl Med 2021;9(5):AB024. doi: 10.21037/ atm.2021.AB024 